\title{
Intake of starch and sugars and total and cause-specific mortality in a Japanese community: the Takayama Study
}

\author{
Chisato Nagata*, Keiko Wada, Michiyo Yamakawa, Kie Konishi, Yuko Goto, Sachi Koda, \\ Fumi Mizuta and Takahiro Uji \\ Department of Epidemiology \& Preventive Medicine, Gifu University Graduate School of Medicine, Gifu 501-1194, Japan
}

(Submitted 14 January 2019 - Final revision received 13 June 2019 - Accepted 1 July 2019)

\begin{abstract}
Studies on the intake of different types of carbohydrates and long-term mortality are sparse. We examined the association of starch, total and each type of sugar and free sugars with the risk of total and cause-specific mortality in a cohort of the general population in Japan. Study subjects were 29079 residents from the Takayama Study, Japan, who responded to a self-administered questionnaire in 1992. Diet was assessed by a validated FFQ at the baseline. Mortality was ascertained during 16 years of follow-up. We noted 2901 deaths ( 974 cancer related and 775 cardiovascular related) in men and 2438 death (646 cancer related and 903 cardiovascular related) in women. In men, intake of starch was inversely associated with total mortality after controlling for covariates (hazard ratio (HR) for the highest quartile $v$. lowest quartile: $0 \cdot 71$; $95 \%$ CI 0.60, 0.84; $\left.P_{\text {trend }}<0 \cdot 001\right)$. Intakes of total sugars, glucose, fructose, sucrose, maltose and free and naturally occurring sugars were significantly positively associated with total mortality in men (HR for the highest $v$. lowest quartile of total sugar: 1.27 ; $95 \%$ CI $1.12,1.45$; $\left.P_{\text {trend }}<0.0001\right)$. Similar relations were observed for cardiovascular mortality and non-cancer, non-cardiovascular mortality in men. In women, there was no significant association between any type of carbohydrates and mortality except that intake of free sugars was significantly positively associated with total and non-cancer, non-cardiovascular mortality. Data suggest that the high intake of starch reduces mortality, whereas the high intake of sugars, including glucose, fructose and sucrose, increases mortality in Japanese men.
\end{abstract}

Key words: Cohort studies: Starches: Sugars: Fructose: Sucrose: Mortality: Japanese

Dietary carbohydrates are a major contributor of postprandial glycaemia. Hyperglycaemia has been associated with the increased risk of diabetes, CVD and some cancer ${ }^{(1-3)}$. Dietary carbohydrates have also been implicated in weight gain ${ }^{(4)}$, hyperlipidaemia $^{(5)}$ and hypertension ${ }^{(6)}$, which are risk factors for these chronic diseases. Therefore, a higher intake of carbohydrates may adversely affect total mortality. A recent large prospective study of eighteen countries found that high carbohydrate intake was associated with higher risk of total mortality ${ }^{(7)}$. However, in our previous study, the consumption of rice, which is a main source of carbohydrates in Japan, was significantly inversely associated with total mortality in Japanese men ${ }^{(8)}$. Sugars come from fruits, milk and sugars, syrups or energy sweeteners that are added to foods during food process or manufacturing $^{(9)}$ and are also classified as carbohydrates. The impact on health of dietary sugars, especially fructose and sucrose, has been a major concern and continues to be a controversial topic $^{(10)}$. These sugars could mechanistically promote the development of diabetes and CVD through liver lipid accumulation, dyslipidaemia, decreased insulin sensitivity and increased uric acid levels ${ }^{(11)}$. The major source of fructose in the diet are fructose-containing sugars (sucrose and high-fructose corn syrup) largely used as free sugar ${ }^{(12)}$. Epidemiological studies have suggested that the consumption of free sugars is associated with cardiometabolic diseases ${ }^{(13-15)}$. However, the majority of evidence is available only from sugar-sweetened beverages. In addition, results from clinical trials do not strongly support a detrimental effect of free sugars on metabolic health ${ }^{(16)}$.

The relationships between the intake of carbohydrates and total mortality may depend on the type of carbohydrates consumed. However, to our knowledge, only one study has prospectively assessed the association of types of sugars with total mortality ${ }^{(17)}$, and only a few prospective studies include some types of carbohydrates in relation to $\mathrm{CVD}^{(18-22)}$. The results of these studies are mixed. Recently, food content data for available carbohydrates have been published in Japan, which enabled us to estimate the intake of each type of carbohydrate ${ }^{(23)}$. We examined the association of types of carbohydrates - including starch, total sugar, sucrose, fructose, maltose, lactose and free and naturally occurring sugars - with total mortality and cause-specific

Abbreviations: E \%, percentage energy; HR, hazard ratio; NIH-AARP, National Institutes of Health-American Association of Retired Persons.

* Corresponding author: C. Nagata, email chisato@gifu-u.ac.jp 
mortality in a population-based cohort of Japanese men and women (the Takayama Study).

\section{Methods \\ Study population}

The Takayama Study cohort was established in 1992 to identify dietary and lifestyle factors in relation to morbidity from cancer and various other diseases. Details on baseline characteristics of study subjects and design of the Takayama Study are described in detail elsewhere ${ }^{(24)}$. All residents who were aged 35 years and over and not hospitalised in Takayama, Gifu Prefecture, Japan ( $n$ 36 990) were invited to the cohort study. A total of 34018 subjects responded. Written informed consent was not obtained at the baseline. The study has been approved by the ethical committee of the Gifu University Graduate School of Medicine.

\section{Assessment of dietary sugars}

Diet over the past 1 year was assessed with a validated 169-item semi-quantitative $\mathrm{FFQ}^{(25)}$. The questionnaire asked participants about their usual frequency of consuming each food item and the usual serving size of each item during the past year. For mixed dishes, component foods were predetermined. A total of 520 foods were covered by the FFQ. Estimations of the intake of individual types of carbohydrates (starch, glucose, fructose, sucrose, maltose and lactose) were based on the use of an available carbohydrate table, a supplement to the Standard Tables of Food Composition, 2015, in Japan, published by the Science and Technology Agency of Japan ${ }^{(26)}$. Total carbohydrate contents have been published before ${ }^{(27)}$. Total sugars represent the sum of monosaccharides (i.e. glucose, fructose and galactose) and disaccharides (i.e. sucrose, lactose, maltose and trehalose). This new table is incomplete for some foods; however, in our study subjects, the sum of starch and total sugar covered $95.0 \%$ of the total carbohydrate intake. In addition, we estimated the individual types of carbohydrates for unlisted thirty-food foods including meat and seafood seasoned with sugar, $50 \%$ fruit juice beverage and Danish pastry by assigning borrowed values from similar products or by estimating based on ingredients and/or common recipes. Finally, the sum of starch and total sugar covered $96.2 \%$ of the total carbohydrate intake. Due to the lack of free sugar values in the database ${ }^{(26)}$, all sugars in sugar, honey, starch sugar, soft drinks, juices, soya beverages, jams, confectioneries (including traditional confectioneries, cakes, buns, pastries, desserts, biscuits, snacks, candies, chocolates), ice cream, meat and seafood seasoned with sugar, yeast bread and breakfast cereals were summed up to yield the intake of free sugars. According to the definition by the $\mathrm{WHO}^{(28)}$, '100\% fruit juices' was considered as free sugars. Conversely, naturally occurring sugars in fruit and vegetables or dairy products were not included. Intake of naturally occurring sugars was estimated by subtracting the free sugar intake from the total sugar intake ${ }^{(29)}$. Intakes of other nutrients were estimated based on these information using the Japanese Standard Tables of Food Composition, 5th revised and enlarged edition ${ }^{(27)}$. A detailed description of the FFQ, along with its reliability and validity, was published previously ${ }^{(25)}$. At the start of the cohort study, the FFQ was validated in subsamples in this population by comparing twelve 1 -d diet records kept over a 1-year period ${ }^{(25)}$. For the present study, validity of estimation of each type of carbohydrate has been additionally checked using the same data set. The Spearman's correlation coefficients between the questionnaire and twelve 1-d diet records kept over a 1-year period for intakes of total energy, total carbohydrates, starch, total sugars, glucose, fructose, sucrose, maltose and lactose were $0 \cdot 44,0 \cdot 34,0 \cdot 31,0 \cdot 28$, $0.46,0.51,0.48,0.35$ and 0.85 , respectively, in men $(n 17)$ and $0.53,0.45,0.31,0 \cdot 60,0 \cdot 68,0.80,0.46,0.56$ and 0.71 , respectively, in women ( $n$ 20).

\section{Subject characteristics and physical activity}

Study subjects responded to a baseline self-administered questionnaire that included questions on demographic characteristics, smoking, diet, physical activity and medical and reproductive histories. Physical activity was assessed by asking the average hours per week spent performing various kinds of activities during the past year. The time per week spent at each intensity of activity was multiplied by its correspondent energy expenditure requirements, expressed as a metabolic equivalent, and summed up to yield a score (metabolic equivalents hours/ week). The details including its validity are described elsewhere ${ }^{(30)}$. Briefly, the correlation coefficients between the daily energy expenditure per body weight measured by the calorie counter for 7 consecutive days and the daily energy expenditure estimated from our questionnaire were 0.69 in men $(n$ 49) and 0.62 in women $(n 32)^{(30)}$.

\section{Data cleaning and exclusions}

Among 34018 respondents, those who incompletely filled baseline questionnaire and FFQ were excluded. Exclusion was also made in the analytical phase of the present study. Fig. 1 shows the flow chart for exclusion process. Finally, 29079 (13 355 men and 15724 women) participants were included in the present analyses.

\section{Follow-up and endpoints}

Information concerning subjects who died or moved away from Takayama City between the baseline (1 September 1992) and 1 October 2008, was obtained from residential registers or family registers. The mean duration of follow-up was $14 \cdot 1$ years. Causes of death were identified from death certificates provided by the Legal Affairs Bureau. They were coded according to the International Classification of Diseases, 10th Revision (ICD-10), which was used to define deaths as follows: cancer (ICD-10: C00-D48), CVD (ICD-10: I00-I99) and all other causes (non-cancer, non-CVD diseases). During the study period, 941 (6.5\%) men and $971(5.7 \%)$ women moved out of Takayama City. Among them, the date of moving was unknown for 104 $(0.7 \%)$ men and $147(0.9 \%)$ women. They were censored at the latest date when they were known to reside in the city. 


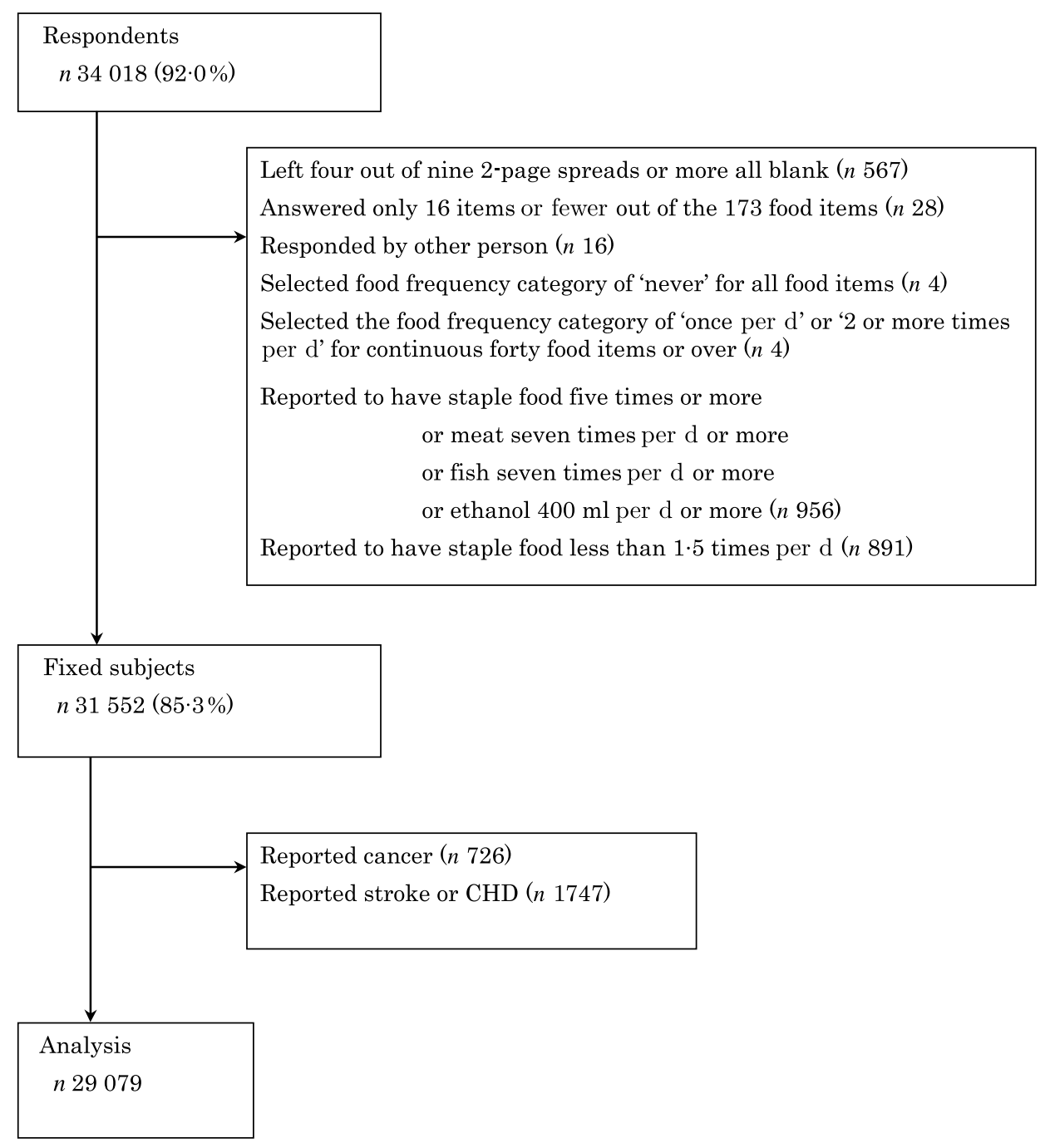

Fig. 1. Flow chart for the exclusion process.

\section{Statistical analyses}

For each participant, person-years of follow-up were calculated from the date of response to the baseline questionnaire to the date of death, the date of emigration out of Takayama or the end of follow-up (1 October 2008), whichever occurred first. Each type of carbohydrate was expressed as percentage energy (E \%). Subjects were divided into sex-specific four equal groups according to the quartile of each carbohydrate. We used the Cox proportional hazards model to estimate the hazard ratios (HR) and $95 \%$ CI for total mortality and cause-specific mortality for each intake category as compared with the lowest intake category. The quartile medians as continuous variables (E\%) were used to assess the linear trend. As we used $\mathrm{E} \%$ values as explanatory variables, the models tested the effect of substituting the explanatory carbohydrate variable for other energy-contributing nutrients not included in the models. Separate models for starch and each of the sugar types were created. First, we included age in the model as a covariate. In our second model, we further adjusted for non-dietary factors including marital status (married, not married or missing), level of education ( $\leq 11,12-14$, $15 \geq$ years or missing), height (in quartile or missing), BMI (in quartile or missing), physical activity (metabolic equivalents hours/week), alcohol consumption (in quartile for men and non-drinkers, drinkers below or above the median, alcohol level for women), smoking status (never, former, current with $\leq 30$ years of smoking, current and $>30$ years of smoking or missing for men and never, former, current or missing for women), history of diabetes and hypertension (yes, no) and menopausal status (premenopausal, postmenopausal or missing; women only). Height and weight were self-reported. Our validity study showed that the correlation coefficients between self-reported and measured height and weight among a subsample were 0.85 for height and 0.97 for weight in men ( $n$ 1187), and the corresponding values were 0.93 and 0.97 , respectively, in women ( $n$ 3412). As alcohol drinkers and smokers were fewer in women than men, the different categorisations for alcohol consumption and smoking status between men and women were used. 
In our third model, we further adjusted for dietary factors including total energy, total fat (E \%), salts $(\mathrm{g} / 4184 \mathrm{~kJ})$, dietary fibre $(\mathrm{g} / 4184 \mathrm{~kJ}$ ) and coffee (cups). For the analyses among men, we further used the energy-partition model ${ }^{(31)}$, in which total energy is partitioned into that contributed by different types of carbohydrate (i.e. starch and total sugar) and that contributed by other sources (fat and protein). Total energy intake is not held constant. The model included adjustment for all non-dietary covariates and dietary factors including intakes of salts, dietary fibre and coffee. Intakes of salts and dietary fibre were expressed in terms of grams. All the statistical analyses were performed using SAS programs. Power calculations showed that the sample size and number of total deaths were sufficiently large to detect an HR of 1.2 (or $0 \cdot 83$ ) for the highest quartile of intake as compared with the lowest, with a statistical power of $80 \%$ and significance level of $5 \%$.

\section{Results}

Mean intakes of starch and total and free sugars were 38.7, 8.6 and $3.9 \mathrm{E} \%$, respectively, in men, and $39.8,10.9$, and $4.8 \mathrm{E} \%$, respectively, in women. The main dietary sources of starch were rice $(76.6 \%$ for men and $72.6 \%$ for women, respectively) and other cereals $(17 \cdot 0 \% / 18 \cdot 0 \%)$. For total sugar, the leading contributor was sweetened beverages (20.6\%) followed by vegetables excluding juice $(17 \cdot 7 \%)$, fruits excluding juice and jam $(12.7 \%)$ and dairy foods excluding ice cream (12.5\%) in men; in women the leading contributor was vegetables excluding juice (18.5\%) followed by sweetened beverages (15.6\%), fruits excluding juice and jam $(15 \cdot 1 \%)$ and dairy foods excluding ice cream $(13.7 \%)$. The main sources of free sugars were sweetened beverages (35.7 and $29.6 \%$ in men and women, respectively), confectioneries (18.4\%/25.0\%) and sugars (16.2\%/15.6\%).

Baseline characteristics of the study population by sex and quartile of starch and total sugars are shown in Table 1. Men with greater intake of starch were more likely to be aged, not married and less educated, and physically less active, and less likely to have reported histories of hypertension and diabetes. They also had lower BMI and lower intake of alcohol, total energy, total fat, dietary fibre, salt and coffee. Men with greater total sugar intake were more likely to be aged, educated, obese and never smokers and less likely to have reported histories of hypertension. They also had lower intake of alcohol and higher intake of total energy, total fat, dietary fibre, salt and coffee. Similar tendency was observed for women. Our questionnaire was designed to measure an individual's relative intakes of nutrients or foods rather than absolute values. Although we presented the mean values for dietary intakes in the table, some of them may be overestimated by our questionnaire.

During the 16 years of follow-up period, there were 2901 male deaths and 2438 female deaths. Intake of starch was significantly inversely and intake of total sugars was significantly positively associated with total, CVD and non-cancer, non-CVD mortality in men after controlling for all covariates (fully-adjusted model) (Table 2). The trends across quartiles were also statistically significant. In the energy-partition model, both starch and total sugar intakes were significantly associated with all-cause mortality (HR for every $418.4 \mathrm{~kJ}$ of starch and total sugar intakes were 0.98; $95 \%$ CI 0.97, 0.997 and 1.07; $95 \%$ CI 1.03, $1 \cdot 10$, respectively) and cardiovascular mortality (HR for every $418.4 \mathrm{~kJ}$ of starch and total sugar intakes were 0.96; $95 \% \mathrm{CI}$ $0.93,0.99$ and $1.08 ; 95 \%$ CI 1.01, 1.15, respectively) in men.

Among the sugars, glucose, fructose, sucrose, maltose and free and naturally occurring sugars were significantly positively associated with total mortality in men (online Supplementary Table S1). Maltose intake was significantly positively associated with cancer mortality in men. For other types, similar associations were observed for mortality from CVD and non-cancer, non-CVD in men except that naturally occurring sugars were not associated with CVD mortality.

In women, intake of starch as well as total sugars was not significantly associated with total and cause-specific mortality (Table 3). Among the sugars, only the intake of free sugars was significantly associated with mortality from total and noncancer, non-CVD mortality (Table S2).

Exclusion of deaths during the first 3 years did not alter the results substantially; the HR of total mortality in men for the highest $v$. lowest quartile of starch and total sugar intake were 0.74 ; $95 \%$ CI 0.62, 0.88; $P_{\text {trend }}=0.0006$ and $1.25 ; 95 \%$ CI 1.09, 1.45, $P_{\text {trend }}=0 \cdot 0003$, respectively.

\section{Discussion}

We found that a higher intake of starch was associated with a decreased risk of total mortality, whereas a higher intake of total sugar, sucrose, fructose, and sucrose intake was associated with increased risk of total mortality in men. Similar associations were observed for CVD mortality and non-cancer, non-CVD mortality in men. So far, only one study, the National Institutes of Health-American Association of Retired Persons (NIH-AARP) Diet and Health Study, examined the association between types of carbohydrates and total mortality ${ }^{(17)}$, though the study included sugars but not starch. In the study, a high intake of total sugars as well as fructose, which is a low-glycaemic index carbohydrate, was weakly but significantly associated with an increased risk of total mortality in men and women. A high intake of sucrose was significantly inversely associated with noncancer, non-CVD mortality in men. The results for total sugar and fructose intake, in relation to total mortality, were similar to our results in men.

More interest has been paid to the association between types of carbohydrates and CVD. In the NIH-AARP Diet and Health Study, there were no significant associations of total sugars or any type of sugars with CVD mortality ${ }^{(17)}$. So far, additional four prospective cohorts examined the associations of starch or sugars with the incidence of or mortality from $\mathrm{CVD}^{(18-22)}$. The results of these studies were inconsistent, though differences in ethnicity and outcomes (incidence or mortality; IHD, cerebrovascular disease or CVD) among studies may be partially explanatory. One mortality study, conducted in China, observed that starch intake in women was significantly positively associated with the IHD mortality; and total sugar intake in men was significantly inversely associated with IHD mortality ${ }^{(22)}$. Among the remaining three incidence studies, one study reported that starch, sucrose and lactose were not associated with a risk of IHD in 
Table 1. Baseline characteristics of study subjects according to the quartile $(Q)$ of starch and total sugar intake (Mean values, numbers and percentages)

\begin{tabular}{|c|c|c|c|c|c|c|c|c|c|c|}
\hline \multirow[b]{2}{*}{ Basic characteristics } & \multicolumn{5}{|c|}{ Starch } & \multicolumn{5}{|c|}{ Total sugars } \\
\hline & Q1 & Q2 & Q3 & $\mathrm{O} 4$ & $P_{\text {trend }}$ & Q1 & Q2 & Q3 & Q4 & $P_{\text {trend }}$ \\
\hline \multicolumn{11}{|l|}{ Men } \\
\hline Range (\% of energy) & $7 \cdot 9-31 \cdot 7$ & $31 \cdot 7-38 \cdot 4$ & $38 \cdot 4-45 \cdot 0$ & $45 \cdot 0-79 \cdot 4$ & & $0.5-5 \cdot 7$ & $5 \cdot 7-7 \cdot 9$ & $7 \cdot 9-10 \cdot 7$ & $10 \cdot 7-40 \cdot 9$ & \\
\hline$n$ & 3339 & 3339 & 3339 & 3338 & & 3339 & 3339 & 3339 & 3338 & \\
\hline Age (years) & 53.4 & $54 \cdot 2$ & 53.7 & $54 \cdot 6$ & 0.0004 & $53 \cdot 3$ & $54 \cdot 0$ & $54 \cdot 1$ & 54.5 & 0.0002 \\
\hline Married (\%) & $91 \cdot 8$ & $92 \cdot 6$ & $92 \cdot 1$ & $89 \cdot 3$ & 0.0002 & $91 \cdot 2$ & 91.9 & $91 \cdot 1$ & $91 \cdot 6$ & 0.89 \\
\hline \multicolumn{11}{|l|}{ Years of education (\%) } \\
\hline$\leqq 11$ & $53 \cdot 2$ & $56 \cdot 2$ & $57 \cdot 0$ & $62 \cdot 2$ & & $61 \cdot 1$ & $56 \cdot 3$ & $54 \cdot 7$ & $56 \cdot 5$ & \\
\hline$\overline{12}-14$ & $32 \cdot 7$ & $31 \cdot 8$ & $30 \cdot 6$ & $29 \cdot 1$ & & $30 \cdot 3$ & 31.9 & $32 \cdot 1$ & 29.9 & \\
\hline$\geqq 15$ & $14 \cdot 1$ & $12 \cdot 1$ & $12 \cdot 4$ & 8.7 & $<0.0001$ & $8 \cdot 6$ & $11 \cdot 8$ & $13 \cdot 3$ & $13 \cdot 7$ & $<0.0001$ \\
\hline \multicolumn{11}{|l|}{ Smoking (\%) } \\
\hline Never & $16 \cdot 0$ & $17 \cdot 0$ & $15 \cdot 9$ & $18 \cdot 2$ & & $12 \cdot 3$ & $15 \cdot 0$ & $17 \cdot 8$ & $22 \cdot 0$ & \\
\hline Former & $28 \cdot 6$ & $27 \cdot 9$ & $28 \cdot 6$ & $27 \cdot 7$ & & $23 \cdot 6$ & $26 \cdot 9$ & 31.9 & $30 \cdot 6$ & \\
\hline Current & $55 \cdot 4$ & $55 \cdot 0$ & $55 \cdot 5$ & $54 \cdot 1$ & 0.07 & $64 \cdot 1$ & $58 \cdot 1$ & $50 \cdot 3$ & $47 \cdot 4$ & $<0.0001$ \\
\hline History of hypertension (\%) & $21 \cdot 1$ & $18 \cdot 9$ & $18 \cdot 5$ & $17 \cdot 2$ & $<0.0001$ & $20 \cdot 7$ & $18 \cdot 2$ & $19 \cdot 3$ & $17 \cdot 5$ & 0.005 \\
\hline History of diabetes mellitus (\%) & $7 \cdot 0$ & 6.7 & $5 \cdot 2$ & 4.9 & $<0.0001$ & $5 \cdot 0$ & 5.7 & $7 \cdot 1$ & $6 \cdot 0$ & 0.07 \\
\hline Height $(\mathrm{cm})$ & $165 \cdot 5$ & $164 \cdot 8$ & $164 \cdot 6$ & 163.9 & $<0.0001$ & $164 \cdot 3$ & $164 \cdot 7$ & $164 \cdot 8$ & $165 \cdot 0$ & $<0.0001$ \\
\hline BMI $\left(\mathrm{kg} / \mathrm{m}^{2}\right)$ & $22 \cdot 7$ & 22.5 & 22.5 & $22 \cdot 3$ & $<0.0001$ & $22 \cdot 4$ & $22 \cdot 4$ & $22 \cdot 5$ & $22 \cdot 7$ & $<0.0001$ \\
\hline Alcohol intake (mg/d) & $67 \cdot 6$ & $47 \cdot 0$ & 34.4 & $18 \cdot 9$ & $<0.0001$ & $60 \cdot 2$ & $43 \cdot 2$ & $36 \cdot 3$ & $28 \cdot 2$ & $<0.0001$ \\
\hline Exercise (MET-h/week) & $28 \cdot 6$ & $27 \cdot 4$ & $27 \cdot 7$ & 24.5 & 0.0002 & $25 \cdot 4$ & $26 \cdot 5$ & $28 \cdot 3$ & $28 \cdot 1$ & 0.005 \\
\hline \multicolumn{11}{|l|}{ Dietary intake } \\
\hline Total energy $(\mathrm{kcal} / \mathrm{d})^{*}$ & 3014 & 2733 & 2561 & 2177 & $<0.0001$ & 2397 & 2513 & 2655 & 2920 & $<0.0001$ \\
\hline Free sugar ( $\%$ of energy/d) & 4.7 & $4 \cdot 2$ & 3.7 & 3.0 & $<0.0001$ & 1.5 & $2 \cdot 7$ & $4 \cdot 1$ & $7 \cdot 2$ & $<0.0001$ \\
\hline Total fat $(\%$ of energy/d) & 23.5 & $21 \cdot 4$ & $19 \cdot 6$ & $16 \cdot 6$ & $<0.0001$ & $17 \cdot 0$ & $20 \cdot 1$ & $21 \cdot 7$ & $22 \cdot 4$ & $<0.0001$ \\
\hline Dietary fibre (g/4184 kJ) & $6 \cdot 6$ & 6.4 & $6 \cdot 0$ & 5.4 & $<0.0001$ & 4.9 & 5.9 & 6.5 & $7 \cdot 2$ & $<0.0001$ \\
\hline Salts (g/4184 kJ) & $6 \cdot 0$ & $5 \cdot 7$ & $5 \cdot 2$ & $4 \cdot 6$ & $<0.0001$ & $4 \cdot 8$ & $5 \cdot 4$ & $5 \cdot 6$ & $5 \cdot 6$ & $<0.0001$ \\
\hline Coffee (cups/d) & 0.89 & 0.87 & 0.88 & 0.78 & $<0.0001$ & 0.77 & 0.85 & 0.86 & 0.93 & $<0.0001$ \\
\hline \multicolumn{11}{|l|}{ Women } \\
\hline Range (\% of energy) & $9 \cdot 9-33 \cdot 1$ & $33 \cdot 1-39 \cdot 0$ & $39.0-45.8$ & $45 \cdot 8-80 \cdot 4$ & & $0.8-8 \cdot 1$ & $8 \cdot 1-10 \cdot 4$ & $10 \cdot 4-13 \cdot 1$ & $13 \cdot 1-42 \cdot 9$ & \\
\hline$n$ & 3931 & 3931 & 3931 & 3931 & & 3931 & 3931 & 3931 & 3931 & \\
\hline Age (years) & $53 \cdot 6$ & 53.9 & 55.4 & 57.5 & $<0.0001$ & 54.7 & 54.6 & 55.0 & $56 \cdot 3$ & $<0.0001$ \\
\hline Married (\%) & $76 \cdot 3$ & $77 \cdot 7$ & 74.7 & $72 \cdot 0$ & $<0.0001$ & $76 \cdot 0$ & $76 \cdot 2$ & $75 \cdot 8$ & $72 \cdot 7$ & 0.0005 \\
\hline \multicolumn{11}{|l|}{ Years of education (\%) } \\
\hline$\leqq 11$ & $60 \cdot 0$ & $62 \cdot 7$ & 66.9 & $75 \cdot 2$ & & 69.5 & 64.9 & 64.9 & 65.7 & \\
\hline$\overline{12}-14$ & 33.7 & $32 \cdot 0$ & $28 \cdot 6$ & $22 \cdot 2$ & & $27 \cdot 5$ & $29 \cdot 8$ & $29 \cdot 8$ & $29 \cdot 4$ & \\
\hline$\geqq 15$ & $6 \cdot 3$ & $5 \cdot 3$ & 4.5 & $2 \cdot 6$ & $<0.0001$ & 3.4 & $5 \cdot 1$ & $5 \cdot 3$ & 4.8 & 0.004 \\
\hline \multicolumn{11}{|l|}{ Smoking (\%) } \\
\hline Never & $80 \cdot 1$ & $82 \cdot 6$ & $84 \cdot 8$ & $82 \cdot 5$ & & $76 \cdot 9$ & $82 \cdot 4$ & $85 \cdot 7$ & $85 \cdot 8$ & \\
\hline Former & $4 \cdot 3$ & $4 \cdot 7$ & $3 \cdot 7$ & 4.7 & & $4 \cdot 3$ & 4.6 & $4 \cdot 2$ & $4 \cdot 4$ & \\
\hline Current & $15 \cdot 6$ & $12 \cdot 7$ & $11 \cdot 4$ & 12.9 & 0.0006 & $18 \cdot 8$ & $13 \cdot 0$ & $10 \cdot 1$ & $10 \cdot 6$ & $<0.0001$ \\
\hline History of hypertension (\%) & $16 \cdot 4$ & $16 \cdot 6$ & $17 \cdot 8$ & $18 \cdot 6$ & 0.005 & $17 \cdot 0$ & $16 \cdot 8$ & $17 \cdot 1$ & $18 \cdot 6$ & 0.0049 \\
\hline History of diabetes mellitus (\%) & 3.0 & 2.5 & $2 \cdot 8$ & 2.5 & 0.37 & $2 \cdot 3$ & $2 \cdot 3$ & 3.0 & $3 \cdot 1$ & 0.01 \\
\hline Postmenopausal (\%) & $56 \cdot 3$ & 55.9 & $58 \cdot 9$ & $64 \cdot 4$ & $<0.0001$ & $55 \cdot 4$ & $56 \cdot 6$ & $59 \cdot 4$ & $64 \cdot 0$ & $<0.0001$ \\
\hline Height (cm) & $152 \cdot 7$ & $152 \cdot 6$ & $151 \cdot 8$ & $151 \cdot 1$ & $<0.0001$ & 151.9 & $152 \cdot 1$ & $152 \cdot 2$ & $152 \cdot 1$ & $0 \cdot 26$ \\
\hline BMI $\left(\mathrm{kg} / \mathrm{m}^{2}\right)$ & $22 \cdot 0$ & $22 \cdot 0$ & $22 \cdot 0$ & $21 \cdot 8$ & $<0.0001$ & $21 \cdot 8$ & $22 \cdot 0$ & $22 \cdot 0$ & $22 \cdot 1$ & $<0.0001$ \\
\hline Alcohol intake (mg/d) & $14 \cdot 4$ & $7 \cdot 7$ & 5.4 & $3 \cdot 3$ & $<0.0001$ & $10 \cdot 9$ & $7 \cdot 6$ & $6 \cdot 3$ & $6 \cdot 2$ & $<0.0001$ \\
\hline Exercise (MET-h/week) & $19 \cdot 4$ & $20 \cdot 9$ & $18 \cdot 4$ & $16 \cdot 5$ & $<0.0001$ & $17 \cdot 3$ & $19 \cdot 2$ & 20.5 & $18 \cdot 3$ & 0.09 \\
\hline \multicolumn{11}{|l|}{ Dietary intake } \\
\hline Total energy $(\mathrm{kcal} / \mathrm{d})^{*}$ & 2603 & 2148 & 1971 & 1808 & $<0.0001$ & 1865 & 2026 & 2166 & 2472 & $<0.0001$ \\
\hline Free sugar ( $\%$ of energy) & $6 \cdot 3$ & $5 \cdot 1$ & 4.5 & 3.4 & $<0.0001$ & 2.5 & $3 \cdot 8$ & 5.0 & $8 \cdot 0$ & $<0.0001$ \\
\hline Total fat $(\%$ of energy/d) & $27 \cdot 1$ & $24 \cdot 6$ & $22 \cdot 1$ & $17 \cdot 5$ & $<0.0001$ & $20 \cdot 0$ & $23 \cdot 2$ & $24 \cdot 1$ & $24 \cdot 1$ & $<0.0001$ \\
\hline Dietary fibre (g/4184 kJ) & $8 \cdot 7$ & $8 \cdot 2$ & $7 \cdot 6$ & 6.5 & $<0.0001$ & $6 \cdot 4$ & $7 \cdot 5$ & $8 \cdot 3$ & $8 \cdot 8$ & $<0.0001$ \\
\hline Salts (g/4184 kJ) & 6.8 & 6.5 & $6 \cdot 1$ & $5 \cdot 1$ & $<0.0001$ & $5 \cdot 6$ & $6 \cdot 2$ & 6.4 & $6 \cdot 2$ & $<0.0001$ \\
\hline Coffee (cups/d) & 0.83 & 0.73 & 0.64 & 0.48 & $<0.0001$ & 0.65 & 0.68 & 0.67 & 0.68 & 0.32 \\
\hline
\end{tabular}

MET, metabolic equivalent.

* To convert energy in kcal to kJ, multiply by 4.184 .

US women ${ }^{(18)}$. The other two studies included starch or total sugars but not types of sugars: there was no association with the risk of IHD and cerebrovascular disease among Europeans ${ }^{(19-21)}$. Additionally, two prospective cohort studies included a single type of sugar - sucrose or fructose ${ }^{(32,33)}$. Sucrose intake was significantly associated with a risk of acute coronary event in the
Swedish population ${ }^{(32)}$. Fructose intake was significantly positively associated with cardiovascular events (IHD, stroke or CVD death) in the Iranian population ${ }^{(33)}$.

White rice is a staple food and the main source of starch in the Japanese diet. Rice intake has been associated with CVD risk factors - including the metabolic syndrome and diabetes - but not 
Table 2. Risk for total and cause-specific mortality in men by the quartiles of carbohydrates intake (Hazard ratios (HR) and $95 \%$ confidence intervals)

\begin{tabular}{|c|c|c|c|c|c|c|c|c|}
\hline & \multirow{2}{*}{$\begin{array}{c}\text { Quartile } 1 \\
\text { HR }\end{array}$} & \multicolumn{2}{|c|}{ Quartile 2} & \multicolumn{2}{|c|}{ Quartile 3} & \multicolumn{2}{|c|}{ Quartile 4} & \multirow[b]{2}{*}{$P_{\text {trend }}$} \\
\hline & & $\mathrm{HR}$ & $95 \% \mathrm{Cl}$ & $\mathrm{HR}$ & $95 \% \mathrm{Cl}$ & $\mathrm{HR}$ & $95 \% \mathrm{Cl}$ & \\
\hline \multicolumn{9}{|l|}{ Total mortality } \\
\hline \multicolumn{9}{|l|}{ Starch } \\
\hline $\begin{array}{l}\text { Median (\% of } \\
\text { energy) }\end{array}$ & $27 \cdot 5$ & \multicolumn{2}{|c|}{$35 \cdot 2$} & \multicolumn{2}{|c|}{$41 \cdot 5$} & \multicolumn{2}{|c|}{$50 \cdot 0$} & \\
\hline No. of deaths & 714 & \multicolumn{2}{|c|}{747} & \multicolumn{2}{|c|}{601} & \multicolumn{2}{|c|}{749} & \\
\hline Age-adjusted HR & 1.0 & 0.97 & $0.88,1.08$ & 0.92 & $0.83,1.03$ & 0.94 & $0.85,1.04$ & $0 \cdot 16$ \\
\hline Multivariate $\mathrm{HR}^{\star}$ & 1.0 & 0.99 & $0.89,1.03$ & 0.93 & $0.83,1.03$ & 0.88 & $0.78,0.98$ & 0.01 \\
\hline Multivariate HR† & 1.0 & 0.92 & $0.82,1.03$ & 0.81 & $0.71,0.92$ & 0.71 & $0.60,0.84$ & $<0.0001$ \\
\hline \multicolumn{9}{|l|}{ Total sugar } \\
\hline $\begin{array}{l}\text { Median (\% of } \\
\text { energy) }\end{array}$ & 4.4 & \multicolumn{2}{|c|}{$6 \cdot 8$} & \multicolumn{2}{|c|}{$9 \cdot 1$} & \multicolumn{2}{|c|}{$13 \cdot 0$} & \\
\hline No. of deaths & 662 & \multicolumn{2}{|c|}{694} & \multicolumn{2}{|c|}{754} & \multicolumn{2}{|c|}{791} & \\
\hline Age-adjusted HR & 1.0 & 0.93 & $0.84,1.04$ & 1.02 & $0.92,1.13$ & 1.00 & $0.90,1.11$ & 0.61 \\
\hline Multivariate $\mathrm{HR}^{\star}$ & 1.0 & 0.96 & $0.96,1.07$ & 1.08 & $0.97,1.20$ & 1.09 & $0.98,1.22$ & 0.03 \\
\hline Multivariate HR† & 1.0 & 1.01 & $0.90,1.13$ & $1 \cdot 18$ & $1.05,1.33$ & 1.27 & $1 \cdot 12,1.45$ & $<0.0001$ \\
\hline \multicolumn{9}{|l|}{ Cancer mortality } \\
\hline Starch & & & & & & & & \\
\hline No. of deaths & 252 & & & & & & & \\
\hline Age-adjusted HR & 1.0 & 0.95 & $0.80,1.13$ & 0.86 & $0.72,1.03$ & 0.87 & $0.73,1.04$ & 0.08 \\
\hline Multivariate $\mathrm{HR}^{*}$ & 1.0 & 0.98 & $0.82,1.17$ & 0.91 & $0.76,1 \cdot 10$ & 0.93 & $0.77,1.14$ & 0.40 \\
\hline Multivariate HR† & 1.0 & 0.95 & $0.79,1.15$ & 0.87 & $0.70,1.09$ & 0.87 & $0.65,1.16$ & 0.27 \\
\hline Total sugar & & & & & & & & \\
\hline No. of deaths & 246 & & & & & & & \\
\hline Age-adjusted HR & 1.0 & 0.94 & $0.78,1.12$ & 0.92 & $0.77,1.10$ & 0.84 & $0.70,1.00$ & 0.05 \\
\hline Multivariate $\mathrm{HR}^{*}$ & 1.0 & 0.99 & $0.83,1.18$ & 1.01 & $0.84,1.21$ & 0.97 & $0.80,1.18$ & 0.81 \\
\hline Multivariate $\mathrm{HR} \dagger$ & 1.0 & 1.00 & $0.83,1.20$ & 1.04 & $0.85,1.27$ & 1.03 & $0.82,1.29$ & 0.77 \\
\hline Cardiovascular mortalit & & & & & & & & \\
\hline Starch & & & & & & & & \\
\hline No. of deaths & 204 & & & & & & & \\
\hline Age-adjusted HR & 1.0 & 0.78 & $0.64,0.96$ & 0.92 & $0.76,1.12$ & 0.87 & $0.71,1.06$ & 0.35 \\
\hline Multivariate $\mathrm{HR}^{\star}$ & 1.0 & 0.81 & $0.66,0.99$ & 0.90 & $0.74,1.11$ & 0.77 & $0.62,0.96$ & 0.047 \\
\hline Multivariate HR† & 1.0 & 0.75 & $0.60,0.93$ & 0.80 & $0.62,1.02$ & 0.62 & $0.45,0.86$ & 0.008 \\
\hline Total sugar & & & & & & & & \\
\hline No. of deaths & 174 & & & & & & & \\
\hline Age-adjusted HR & 1.0 & 0.84 & $0.68,1.04$ & 1.03 & $0.84,1.26$ & 1.04 & $0.85,1.27$ & 0.26 \\
\hline Multivariate $\mathrm{HR}^{\star}$ & 1.0 & 0.87 & $0.70,1.08$ & 1.07 & $0.87,1.32$ & 1.12 & $0.91,1.38$ & 0.08 \\
\hline Multivariate HR† & 1.0 & 0.93 & $0.74,1 \cdot 16$ & $1 \cdot 21$ & $0.96,1.52$ & 1.39 & $1.08,1.78$ & 0.001 \\
\hline Non-cancer, non-cardic & mortality & & & & & & & \\
\hline Starch & & & & & & & & \\
\hline No. of deaths & 258 & & & & & & & \\
\hline Age-adjusted HR & 1.0 & 1.14 & $0.97,1.35$ & 0.99 & $0.83,1.17$ & 1.06 & $0.89,1.25$ & 0.93 \\
\hline Multivariate $\mathrm{HR}^{\star}$ & 1.0 & $1 \cdot 14$ & $0.97,1.35$ & 0.94 & $0.79,1 \cdot 13$ & 0.90 & $0.75,1.08$ & 0.08 \\
\hline Multivariate HR† & 1.0 & 1.03 & $0.86,1.22$ & 0.78 & $0.63,0.95$ & 0.64 & $0.49,0.84$ & 0.0002 \\
\hline Total sugar & & & & & & & & \\
\hline No. of deaths & 240 & & & & & & & \\
\hline Age-adjusted HR & 1.0 & 1.00 & $0.84,1.19$ & $1 \cdot 12$ & $0.95,1.33$ & 1.13 & $0.95,1.33$ & 0.09 \\
\hline Multivariate $\mathrm{HR}^{*}$ & 1.0 & 1.01 & $0.85,1.20$ & 1.17 & $0.98,1.39$ & 1.21 & $1.02,1.61$ & 0.01 \\
\hline Multivariate HR $\dagger$ & 1.0 & 1.09 & $0.91,1.31$ & 1.32 & $1.09,1.60$ & 1.47 & $1.19,1.80$ & $<0.0001$ \\
\hline
\end{tabular}

* Adjusted for non-dietary factors including age, height, BMI, physical activity, smoking status, alcohol consumption, education, marital status and histories of diabetes and hypertension.

† Additionally adjusted for dietary factors including total energy and intakes of fat, salt, dietary fibre and coffee.

with CVD mortality ${ }^{(34)}$. A meta-analysis of five prospective studies including four Japanese studies observed that high rice intake was related to a modest reduction in the risk of mortality in men but not in women ${ }^{(35)}$. Starch is the main source of carbohydrates in Japanese diet. In fact, the intake level of total sugars in our study was lower than those in other populations (e.g. the median intakes of total sugars were about $21 \mathrm{E} \%$ and $23 \mathrm{E} \%$ in men and women, respectively, according to the NIH-AARP Diet and Health Study ${ }^{(17)}$, and total sugar intake ranged $15-21 \mathrm{E} \%$ in European countries $\left.{ }^{(36)}\right)$. Total carbohydrate intake was reported to be somewhat lower among North American and European populations ${ }^{(7)}$. Inconsistent findings on the type of carbohydrate and CVD or total death across studies may also be due to these different food cultures (staple foods and food sources of carbohydrate). The primary role of carbohydrates is to provide energy to cells in the body. Starch from rice may work as a fuel and favour better survival, while an excess intake of other carbohydrates may, rather, be associated with an increased risk in Japanese men. As mentioned above, there are plausible mechanisms that support the suggestion that sucrose or fructose can increase the risk of cardiometabolic disease, which may lead to increased mortality. Unfavourable metabolic consequences of 
Table 3. Risk of total and cause-specific mortality in women by the quartiles of dietary carbohydrates (Hazard ratios (HR) and $95 \%$ confidence intervals)

\begin{tabular}{|c|c|c|c|c|c|c|c|c|}
\hline & \multirow{2}{*}{$\frac{\text { Quartile } 1}{\mathrm{HR}}$} & \multicolumn{2}{|c|}{ Quartile 2} & \multicolumn{2}{|c|}{ Quartile 3} & \multicolumn{2}{|c|}{ Quartile 4} & \multirow[b]{2}{*}{$P_{\text {trend }}$} \\
\hline & & $\mathrm{HR}$ & $95 \% \mathrm{Cl}$ & $\mathrm{HR}$ & $95 \% \mathrm{Cl}$ & HR & $95 \% \mathrm{Cl}$ & \\
\hline \multicolumn{9}{|l|}{ Total mortality } \\
\hline \multicolumn{9}{|l|}{ Starch } \\
\hline Median (\% of energy) & $29 \cdot 3$ & \multicolumn{2}{|c|}{$\begin{array}{c}36 \cdot 2 \\
494\end{array}$} & \multirow{2}{*}{\multicolumn{2}{|c|}{$\begin{array}{l}42.0 \\
651\end{array}$}} & \multicolumn{2}{|c|}{$51 \cdot 1$} & \\
\hline No. of deaths & 482 & \multicolumn{2}{|c|}{494} & & & \multicolumn{2}{|c|}{811} & \\
\hline Age-adjusted HR & 1.0 & 0.94 & $0.83,1.07$ & 1.06 & $0.94,1.19$ & 1.09 & $0.97,1.22$ & 0.04 \\
\hline Multivariate $\mathrm{HR}^{*}$ & 1.0 & 0.94 & $0.83,1.06$ & 1.00 & $0.89,1.13$ & 1.01 & $0.90,1 \cdot 14$ & 0.55 \\
\hline Multivariate $\mathrm{HR} \dagger$ & 1.0 & 0.88 & $0.77,1.01$ & 0.91 & $0.79,1.05$ & 0.86 & $0.72,1.03$ & 0.16 \\
\hline \multicolumn{9}{|l|}{ Total sugar } \\
\hline Median (\% of energy) & $6 \cdot 6$ & \multirow{2}{*}{\multicolumn{2}{|c|}{$\begin{array}{c}9.3 \\
579\end{array}$}} & \multirow{2}{*}{\multicolumn{2}{|c|}{$\begin{array}{l}11.6 \\
556\end{array}$}} & \multirow{2}{*}{\multicolumn{2}{|c|}{$\begin{array}{l}15.4 \\
649\end{array}$}} & \\
\hline No. of deaths & 654 & & & & & & & \\
\hline Age-adjusted HR & 1.0 & 0.87 & $0.77,0.97$ & 0.84 & $0.75,0.94$ & 0.92 & $0.83,1.03$ & 0.22 \\
\hline Multivariate $\mathrm{HR}^{*}$ & 1.0 & 0.91 & $0.82,1.02$ & 0.91 & $0.81,1.02$ & 0.97 & $0.87,1.08$ & 0.76 \\
\hline Multivariate $\mathrm{HR} \dagger$ & 1.0 & 0.94 & $0.83,1.05$ & 0.95 & $0.84,1.08$ & 1.04 & $0.92,1.18$ & 0.36 \\
\hline \multicolumn{9}{|l|}{ Cancer mortality } \\
\hline \multicolumn{9}{|l|}{ Starch } \\
\hline No. of deaths & 149 & \multicolumn{2}{|c|}{146} & \multicolumn{2}{|c|}{169} & & & \\
\hline Age-adjusted HR & 1.0 & 0.95 & $0.76,1.19$ & 1.02 & $0.81,1.27$ & 0.97 & $0.78,1.21$ & 0.04 \\
\hline Multivariate $\mathrm{HR}^{\star}$ & 1.0 & 0.95 & $0.76,1.20$ & 1.01 & $0.80,1.26$ & 0.95 & $0.76,1.19$ & 0.75 \\
\hline Multivariate HR $\dagger$ & 1.0 & 0.90 & $0.71,1.15$ & 0.91 & $0.70,1.19$ & 0.78 & $0.55,1.11$ & 0.19 \\
\hline Total sugar & & & & & & & & \\
\hline No. of deaths & 158 & & & & & & & \\
\hline Age-adjusted HR & $1 \cdot 0$ & 0.99 & $0.80,1.24$ & 0.96 & $0.77,1 \cdot 20$ & 1.03 & $0.83,1.27$ & 0.90 \\
\hline Multivariate $\mathrm{HR}^{*}$ & 1.0 & 1.01 & $0.81,1.26$ & 1.00 & $0.80,1.24$ & 1.04 & $0.84,1.29$ & 0.74 \\
\hline Multivariate $\mathrm{HR} \dagger$ & 1.0 & 1.02 & $0.81,1.28$ & 0.99 & $0.77,1.27$ & 1.02 & $0.79,1.32$ & 0.92 \\
\hline Cardiovascular mortality & & & & & & & & \\
\hline Starch & & & & & & & & \\
\hline No. of deaths & 164 & & & & & & & \\
\hline Age-adjusted HR & 1.0 & 0.96 & $0.77,1 \cdot 18$ & $1 \cdot 12$ & $0.92,1.37$ & 1.07 & $0.88,1.29$ & 0.32 \\
\hline Multivariate $\mathrm{HR}^{*}$ & 1.0 & 0.96 & $0.77,1.19$ & 1.07 & $0.88,1.31$ & 1.01 & $0.83,1.22$ & 0.80 \\
\hline Multivariate $\mathrm{HR} \dagger$ & 1.0 & 0.89 & $0.71,1.12$ & 0.95 & $0.75,1.19$ & 0.85 & $0.63,1.14$ & 0.37 \\
\hline Total sugar & & & & & & & & \\
\hline No. of deaths & 258 & & & & & & & \\
\hline Age-adjusted HR & 1.0 & 0.81 & $0.67,0.97$ & 0.75 & $0.62,0.90$ & 0.86 & $0.72,1.03$ & 0.66 \\
\hline Multivariate $\mathrm{HR}^{*}$ & 1.0 & 0.85 & $0.71,1.02$ & 0.81 & $0.67,0.97$ & 0.89 & $0.75,1.07$ & 0.25 \\
\hline Multivariate $\mathrm{HR} \dagger$ & 1.0 & 0.86 & $0.71,1.04$ & 0.84 & $0.69,1.04$ & 0.99 & $0.81,1.22$ & 0.83 \\
\hline Non-cancer, non-cardiovasc & cortality & & & & & & & \\
\hline Starch & & & & & & & & \\
\hline No. of deaths & 169 & & & & & & & \\
\hline Age-adjusted HR & 1.0 & 0.91 & $0.74,1 \cdot 13$ & 1.01 & $0.83,1.24$ & 1.17 & $0.97,1.41$ & 0.02 \\
\hline Multivariate $\mathrm{HR}^{*}$ & 1.0 & 0.89 & $0.72,1 \cdot 11$ & 0.93 & $0.76,1.13$ & 1.04 & $0.86,1.26$ & 0.36 \\
\hline Multivariate HR† & 1.0 & 0.86 & $0.69,1.08$ & 0.87 & $0.69,1.10$ & 0.92 & $0.68,1.24$ & 0.73 \\
\hline Total sugar & & & & & & & & \\
\hline No. of deaths & 238 & & & & & & & \\
\hline Age-adjusted HR & 1.0 & 0.84 & $0.70,1.01$ & 0.86 & $0.71,1.04$ & 0.93 & $0.78,1.12$ & 0.21 \\
\hline Multivariate $\mathrm{HR}^{*}$ & 1.0 & 0.91 & $0.76,1 \cdot 10$ & 0.96 & $0.79,1.16$ & 1.01 & $0.84,1 \cdot 21$ & 0.75 \\
\hline Multivariate HR† & 1.0 & 0.95 & $0.78,1.16$ & 1.02 & $0.83,1.25$ & 1.09 & $0.88,1.35$ & 0.32 \\
\hline
\end{tabular}

* Adjusted for non-dietary factors including age, height, BMI, physical activity, smoking status, alcohol consumption, education, marital status, menopausal status and history of diabetes and hypertension.

† Additionally adjusted for dietary factors including total energy and intakes of fat, salt, dietary fibre and coffee.

consuming rice or a high-glycaemic index carbohydrates in women have been suggested ${ }^{(37,38)}$, and this may partially explain the lack of inverse association between starch intake and mortality in women in the present study. Nonetheless, our results were not similar to those reported among Chinese men where rice is consumed as a staple food ${ }^{(22)}$. Further studies of these associations in different populations are needed.

Positive associations of naturally occurring and free sugars with mortality in men also support the possible effects of sucrose and fructose. Nonetheless, the intakes of total sugars, glucose, fructose and sucrose were highly correlated $(r>0.67)$, and, thus, we could not distinguish the effects of these types of sugars on mortality.
To our knowledge, three studies assessed the association of free sugars with mortality not restricted to the intake of sugar-sweetened beverages. The NIH-AARP Diet and Health Study reported that free sugars and added sucrose were significantly inversely associated with non-cancer, non-CVD mortality in men, whereas added fructose was significantly positively associated with total mortality in women ${ }^{(17)}$. The remaining two studies focused on CVD mortality; the association was significantly positive in the US adults ${ }^{(39)}$ and significantly inverse in the Chinese elderly ${ }^{(40)}$. The definitions for free sugars are not standardised and slightly differed among studies. In our study, either free sugars or naturally occurring sugars was significantly positively associated with total and non-cancer, non-CVD mortality 
in men. These results would not support the hypothesis that free sugar intake was uniquely associated with the risk of mortality relative to other types of sugar. The results also may lessen the concern that the intake of free sugar is a sole indicator of an unhealthy lifestyle. However, we cannot deny residual confounding effects, especially considering that only free sugar intake was significantly associated with total and non-cancer, non-CVD mortality in women.

Strengths of our study include the prospective design, validation of dietary questionnaire, representation of the general population, information on potential confounders and a high rate and length of follow-up. Our study has several limitations. As mentioned above, we cannot deny effects of confounding due to unknown factors or residual confounding, especially on the association between free sugar intake and mortality in women. The use of mortality instead of incidence data disabled us distinguishing the effect of carbohydrates on incidence, survival or both. The sample size was limited, which precluded analyses on causes with small numbers of deaths. Carbohydrate intake was estimated through a single dietary assessment. While FFQ was validated, the correlation coefficients between FFQ and the diet records were low especially for starch and total sugar in men. Therefore, misclassification of subjects according to these intakes is inevitable. However, the poor validation results may in part be due to inadequate validation sample.

In summary, we found that different types of carbohydrates, starches and sugars have different associations with total and cause-specific mortality in men. The high intake of starch and low intake of sugars - including glucose, fructose and sucrose may favour longevity of Japanese men. However, these findings are new, and additional studies on the association between types of carbohydrates and mortality are needed.

\section{Acknowledgements}

The authors thank Dr Shougen Matsushita and Mr. Takehiko Minaguchi for their help in data collection.

This work was supported by grant from the Ministry of Education, Culture, Sports, Science, and Technology, Japan. The funder had no role in the design, analysis or writing of this article.

C. N. designed research and wrote paper; K. W., M. Y. and K. K. conducted research; Y. G., S. K., F. M. and T. U. analysed the data. All authors read and approved the final manuscript.

None of the authors had any conflicts of interest to declare.

\section{Supplementary material}

To view supplementary material for this article, please visit https://doi.org/10.1017/S0007114519001661

\section{References}

1. Coutinho M, Gerstein HC, Wang Y, et al. (1999) The relationship between glucose and incident cardiovascular event: a metaregression analysis of published data from 20 studies of
95783 individuals followed for 12.4 years. Diabetes Care $\mathbf{4 8}$, 937-942.

2. Unwin N, Shaw J, Zimmet P, et al. (2002) Impaired glucose tolerance and impaired fasting glycaemia: the current status on definition and intervention. Diabet Med 19, 708-723.

3. Scappaticco L, Maiorino MI, Bellastella G, et al. (2017) Insights into the relationships between diabetes, prediabetes, and cancer. Endocrine 56, 231-239.

4. Te Morenga L, Mallard S \& Mann J (2012) Dietary sugars and body weight: systematic review and meta-analyses of randomized controlled trials and cohort studies. BMJ 346, e7492.

5. Siri PW \& Krauss RM (2005) Influence of dietary carbohydrate and fat on LDLand HDL particle distributions. Curr Atheroscler Rep 7, 455-459.

6. Klein KV \& Kiat H (2015) The mechanisms underlying fructose-induced hypertension: a review. J Hypertens 33, 912-920.

7. Dehghan M, Mente A, Zhang X, et al. (2017) Associations of fats and carbohydrate intake with cardiovascular disease and mortality in 18 countries from five continents (PURE): a prospective cohort study. Lancet 390, 2050-2062.

8. Nagata C, Wada K, Tsuji M, et al. (2014) Dietary glycemic index and glycemic load in relation to all-cause and cause-specific mortality in a Japanese community: the Takayama study. Br J Nutr 112, 2010-2017

9. Mela DJ \& Woolner EM (2018) Perspective: total, added, or free? What kind of sugars should be talking about? Adv Nutr 9, 63-69.

10. Kahn TA \& Sievenpiper JL (2016) Controversies about sugars: results from systematic reviews and meta-analyses on obesity, cardiometabolic disease and diabetes. Eur J Nutr 55, Suppl. 2, S25-S43.

11. Dekker MJ, Su Q, Baker C, et al. (2010) Fructose: a highly lipogenic nutrient implicated in insulin resistance, hepatic steatosis, and the metabolic syndrome. Am J Physiol Endocrinol Metab 299, E685-E694.

12. Malik VS \& Hu FB (2015) Fructose and cardiometabolic health: what the evidence from sugar-sweetened beverages tells us. J Am Coll Cardiol 66, 1615-1624.

13. de Koning L, Malik VS, Rimm EB, et al. (2011) Sugar-sweetened and artificially sweetened beverage consumption and risk of type 2 diabetes. Am J Clin Nutr 93, 1321-1327.

14. de Koning L, Malik VS, Rimm EB, et al. (2012) Sweetened beverage consumption, incident coronary heart disease, and biomarkers of risk in men. Circulation 125, 1735-1741.

15. Fung TT, Malik V, Rexrode KM, et al. (2009) Sweetened beverage and risk of coronary heart disease in women. Am J Clin Nutr 89, 1037-1042.

16. Rippe JM \& Angelopoulos TJ (2013) Sucrose, high-fructose corn syrup, and fructose, their metabolism and potential health effects: what do we really know? Adv Nutr 4, 236-245.

17. Tasevska N, Park Y, Jiao L, et al. (2014) Sugars and risk of mortality in the NIH-AARP Diet and Health Study. Am J Clin Nutr 99, 1077-1088.

18. Liu S, Willett WC, Stampfer MJ, et al. (2000) A prospective study of dietary glycemic load, carbohydrate intake, and risk of coronary heart disease in US women. Am J Clin Nutr 71, $1455-1461$.

19. Beulens JW, de Bruijne LM, Stolk RP, et al. (2007) High dietary glycemic load and glycemic index increase risk of cardiovascular disease among middle-aged women. a populationbased follow-up study: a population-based follow-up study. J Am Coll Cardiol 50, 14-21.

20. Sieri S, Brighenti F, Agnoli C, et al. (2013) Dietary glycemic load and glycemic index and risk of cerebrovascular disease in the EPICOR cohort. Plos One 8, e62625. 
21. Sieri S, Krogh V, Berrino F, et al. (2010) Dietary glycemic load and index and risk of coronary heart disease in a large Italian cohort. The EPICOR study. Arch Intern Med 170, 640-647.

22. Rebella SA, Koh H, Chen C, et al. (2014) Amount, type, and sources of carbohydrates in relation to ischemic heart disease mortality in a Chinese population: a prospective cohort study. Am J Clin Nutr 100, 53-64.

23. Yasui $T$ (2015) Advances in food composition tables of Japanamino acid, fatty acid and available carbohydrate tables. J Nutr Sci Vitaminol 61, S28-S30.

24. Shimizu H (1996) The Basic Report on Takayama Study. Gifu: Department of Public Health, Gifu University School of Medicine.

25. Shimizu H, Ohwaki A, Kurisu Y, et al. (1999) Validity and reproducibility of a quantitative food frequency questionnaire for a cohort study in Japan. Jpn J Clin Oncol 29, 38-44.

26. Office for Resources, Policy Division Science and Technology Policy Bureau (2015) Standard tables of food composition in Japan - 2015 - (seventh revised edition) - available carbohydrates, polyols and organic acids. http://www.mext.go.jp/en/ policy/science_technology/policy/title01/detail01/sdetail01/ 1388557.htm (accessed September 2019).

27. Council for Science and Technology, Ministry of Education C, Sports, Science and Technology, Japan, ed. (2005) Standard Tables of Food Composition in Japan (5th revised and enlarged edition) (in Japanese). Tokyo: National Printing Bureau.

28. World Health Organization (2015) Guideline: Sugars Intake for Adults and Children. Geneva: WHO.

29. Karrtinen NE, Simila ME, Kanerva N, et al. (2017) Naturally occurring and added sugar in relation to macronutrient intake and food consumption: results from a population-based study in adults. J Nutr Sci 6, e7.

30. Suzuki I, Kawakami N \& Shimizu H (1998) Reliability and validity of a questionnaire for physical activity in epidemiological studies. J Epidemiol 8, 152-159 (supplementary comment: J Epidemiol 2002;12, 54).
31. Kipnis V, Freedman LS, Brown CC, et al. (1993) Interpretation of energy adjustment models for nutritional epidemiology. AmJ Epidemiol 137, 1376-1380.

32. Warfa K, Drake I, Wallström P, et al. (2016) Association between sucrose intake and acute coronary event risk and effect modification by lifestyle factors: Malmö Diet and Cancer Cohort Study. Br J Nutr 116, 1611-1620.

33. Bahadoran Z, Mirmiran P, Tohidi M, et al. (2017) Longitudinal associations of high-fructose diet with cardiovascular events and potential risk factors: Tehran Lipid and Glucose Study. Nutrients 9, 872 .

34. Izadi V \& Azadbakht L (2015) Is there any association between rice consumption and some of the cardiovascular diseases risk factors? A systemic review. ARYA Atheroscler 11, Suppl. 1, 109-115.

35. Saneei P, Larijani B \& Esmaillzadeh A (2016) Rice consumption, incidence of chronic diseases and risk of mortality: metaanalysis of cohort studies. Public health Nutr 20, 233-244.

36. Azais-Braesco V, Sluik D, Maillot M, et al. (2017) A review of total \& added sugar intakes and dietary sources in Europe. Nut J 16, 6.

37. Kim K, Yun SH, Choi BY, et al. (2008) Cross-sectional relationship between dietary carbohydrate, glycaemic index, glycaemic load and risk of the metabolic syndrome in a Korean population. Br J Nutr 106, 576-584.

38. Hare-Bruun H, Nielsen BM, Grau K, et al. (2008) Should glycemic index and glycemic load be considered in dietary recommendations? Nutr Rev 66, 569-590.

39. Yang Q, Zhang Z, Gregg EW, et al. (2014) Added sugar intake and cardiovascular disease mortality among US adults. JAMA Intern Med 174, 516-524.

40. Liu ZM, Tse LA, Chan D, et al. (2018) Dietary sugar intake was associated with increased body fatness but decreased cardiovascular mortality in Chinese elderly: an 11-year prospective study of $\mathrm{Mr}$ and Ms OS of Hong Kong. Int J Obes 42, 808 . 